\title{
Effect of individualized diabetes education for type 2 diabetes mellitus: a single-center randomized clinical trial.
}

\author{
Min-Hua Fan ${ }^{1}$, Bing-Tong Huang, ${ }^{1}$, Ying-Chun Tang, ${ }^{1}$, \\ Xiu-Hua Han, ${ }^{1}$ Wei-Wei Dong, ${ }^{1}$, Le-Xin Wang, ${ }^{2,3}$
}

1. Department of Endocrinology.

2. Cardiology, Liaocheng People's Hospital and Liaocheng Clinical School of Taishan Medical University, Liaocheng, Shandong, 252000, P.R.China

3. School of Biomedical Sciences, Charles Sturt University, Wagga Wagga, NSW 2650, Australia.

\begin{abstract}
Background: To evaluate the effect of individualized education for patients with type 2 diabetes mellitus (T2DM).

Methods: A total of 280 patients (158 males, mean age $63 \pm 10$ years) with T2DM were randomly divided into study and control group. Eysenck Personality questionnaire was used to assess the personality of the patients in the study group, which was provided us one-on-one counseling and individualized management plan. Group education was provided to the control group. Results: At the end of the study, the body mass index $\left(21.5 \pm 2.5\right.$ vs $\left.23.6 \pm 1.6 \mathrm{~kg} / \mathrm{m}^{2}, \mathrm{P}=0.002\right)$, waist circumference $(83.7 \pm 6.4$ vs $85.7 \pm 7.7 \mathrm{~cm}, \mathrm{P}=0.03)$, fasting blood glucose $(6.0 \pm 0.8$ vs $6.9 \pm 2.1 \mathrm{mmol} / \mathrm{L}, \mathrm{P}=0.004), \mathrm{HbA} 1 \mathrm{c}(6.2 \pm 0.6 \%$ vs $6.9 \pm 3.1 \%, \mathrm{P}$ $=0.03)$, systolic blood pressure $(130.1 \pm 8.8$ vs $135.1 \pm 8.4 \mathrm{mmHg}, \mathrm{P}=0.003)$, triglyceride $(1.21 \pm 0.66$ vs $1.46 \pm 0.58 \mathrm{mmol} / \mathrm{L})$ and low-density lipoprotein $(2.36 \pm 0.44$ vs $2.84 \pm 0.64 \mathrm{mmol} / \mathrm{L}, \mathrm{P}=0.03)$ in the study group was lower than in the control group.

Conclusion: Individualized diabetes education is more effective than group education in facilitating the control of type 2 diabetes.

Keywords: Individualization; type 2 diabetes; health education; blood glucose; blood pressure.

DOI: http://dx.doi.org/10.4314/ahs.v16i4.34

Cite as: Fan M-H, Huang B-T, Tang Y-C, Han X-H, Dong W-W, WangL-X. Effect of individualized diabetes education for type 2 diabetes mellitus: a single-center randomized clinical trial. Afri Health Sci.2016;16(4): 1157-1162. http:/ / dx.doi.org/10.4314/abs.v16i4.34
\end{abstract}

\section{Introduction}

Diabetes education plays a pivotal role in the management of type 2 diabetes mellitus (T2DM). Recent clinical trials have confirmed that diabetes education significantly improved the percentage of patients achieving therapeutic targets, and increased medication adherence and self-care performance. ${ }^{1,2}$ Diabetic education was also associated with a lower rate of chronic complications from the chronic illness ${ }^{1}$ In patients with T2DM, personality traits seem to be associated with the level of glycemic

\footnotetext{
Corresponding author:

Lexin Wang,

School of Biomedical Sciences,

Charles Sturt University

Wagga Wagga, NSW 2678, Australia.

Phone: +61 2 69332905,

Fax: +61269332587,

E-mail: lwang@csu.edu.au
}

control. ${ }^{3}$ High neuroticism scores were associated with a higher level of glycosylated haemoglobin (HbA1c) concentrations in patients with T1DM. ${ }^{4}$ A recent meta-analysis showed that adverse psychosocial factors, such as stress-prone personality or coping style, were associated with poor control of type 1 and type 2 diabetes. ${ }^{5}$ Stress management training was associated with a clinically significant reduction in HbA1 $c^{6}$ Furthermore, experimental data suggested that interventions based on the personality of the individuals improved the success of the diabetes treatment.

Most current diabetes education programs are knowledge based and have emphasis on lifestyle changes, self-care and active participation in disease management. ${ }^{1,2}$, These education sessions were often delivered to a group of $\mathrm{pa}$ tients. ${ }^{1,2.8}$ There is little information about the effect of individualized and personality specific diabetes education on the management outcomes of T2DM. In the present study, we evaluated the clinical outcomes of a group of

African Health Sciences Vol 16 Issue 4, December, 2016 
T2DM patients who received an individualized diabetes education program taking into consideration their personality traits.

\section{Patients and methods}

\section{Patient selection}

This study was approved by the institutional review board of our hospital. Written informed consent was obtained from all participants before the study. Between October 2008 and October 2010, 365 hospitalized patients with T2DM were screened for this study.

The selection criteria were: a) Established diagnosis of T2DM according to the 1999 World Health Organiza- tion diagnostic criteria; b) Able to participate follow-up studies after discharge; c) Provision of written informed consent. Exclusion criteria were: a) Known psychological or psychiatric disorders, such as major depression or generalize anxiety disorders; b) Severe co-morbidities, such as renal failure, hepatic dysfunction, cancer or stroke; c) Uncontrolled complications from diabetes, such as acidosis, infection, peripheral vascular disease resulting amputation or leg ulcer.

Eighty-five patients were excluded from this study due to inability to attend regular follow-ups $(\mathrm{n}=54)$ or severe complications from diabetes $(\mathrm{n}=31)$. The general characteristics of the 280 enrolled patients (158 males, mean age $63 \pm 10$ years) are listed in table 1 .

Table 1. Comparison of baseline data between the study and control group.

\begin{tabular}{|c|c|c|c|}
\hline & $\begin{array}{l}\text { Study } \\
(n=138)\end{array}$ & $\begin{array}{l}\text { Control } \\
(n=138)\end{array}$ & $\boldsymbol{P}$ \\
\hline Age (yrs) & $62.94 \pm 10.72$ & $64.89 \pm 10.14$ & 0.26 \\
\hline Sex (male) & $78(56.5 \%)$ & $80(58.0 \%)$ & 0.34 \\
\hline \multicolumn{4}{|l|}{ Education level } \\
\hline Primary & $80(58.0 \%)$ & $88(63.7 \%)$ & 0.71 \\
\hline High school & $32(23.2 \%)$ & $28(20.3 \%)$ & 0.69 \\
\hline Tertiary & $26(18.8 \%)$ & $22(15.9 \%)$ & 0.58 \\
\hline $\begin{array}{l}\text { Duration of DM } \\
\text { (yrs) }\end{array}$ & $11.4 \pm 4.8$ & $11.6 \pm 5.0$ & 0.66 \\
\hline BMI $\left(\mathrm{kg} / \mathrm{m}^{2}\right)$ & $24.25 \pm 3.71$ & $24.32 \pm 3.89$ & 0.76 \\
\hline $\begin{array}{l}\text { Waist } \\
\text { circumference }(\mathrm{cm})\end{array}$ & $86.9 \pm 6.01$ & $86.7 \pm 6.22$ & 0.78 \\
\hline $\begin{array}{l}\text { Fasting blood } \\
\text { glucose }(\mathbf{m m o l} / \mathbf{L})\end{array}$ & $8.60 \pm 3.02$ & $8.72 \pm 3.39$ & 0.95 \\
\hline $\begin{array}{l}\text { Post-prandial } \\
\text { glucose }(\mathbf{m m o l} / \mathbf{L})\end{array}$ & $13.72 \pm 4.91$ & $13.93 \pm 4.56$ & 0.63 \\
\hline HbA1c & $9.61 \pm 1.92$ & $9.80 \pm 1.98$ & 0.38 \\
\hline SBP(mm Hg) & $142.38 \pm 17.55$ & $139.82 \pm 15.99$ & 0.46 \\
\hline DBP(mm Hg) & $86.18 \pm 10.80$ & $87.93 \pm 11.63$ & 0.41 \\
\hline $\begin{array}{l}\text { Triglyceride } \\
(\mathrm{mmol} / \mathrm{L})\end{array}$ & $1.41 \pm 0.91$ & $1.43 \pm 0.80$ & 0.95 \\
\hline LDL (mmol/L) & $3.20 \pm 0.80$ & $3.16 \pm 0.79$ & 0.69 \\
\hline HDL(mmol/L) & $1.20 \pm 0.20$ & $1.43 \pm 0.25$ & 0.29 \\
\hline $\begin{array}{l}\text { Total } \\
\text { cholesterol(mmol/L) }\end{array}$ & $4.88 \pm 0.82$ & $4.78 \pm 0.67$ & 0.63 \\
\hline
\end{tabular}

BMI: Body mass index. SBP and DBP: systolic and diastolic blood pressure; LDL and HDL: low and high density lipoprotein. 


\section{Personality assessment}

The personality in the study group was assessed by Eysenck Personality Questionnaire.?

For practical purposes of this study, a patient's personality is classified into one of the following 4 categories: stable extraversion (outgoing, talkative, responsive and easygoing); unstable extraversion (touchy, restless, excitable, changeable or impulsive); stable introversion (calm, even-tempered, reliable, controlled, peaceful, thoughtful, careful, and passive); and unstable introversion (quiet, reserved, pessimistic, sober, rigid, anxious, or moody).

\section{Diabetes education}

Eight practicing nurses underwent a 2 -week training course on diabetes education and Eysenck Personality Questionnaire assessment. A written evaluation was conducted at the end of the training course to ensure all the nursing educators were familiar with the education and personality assessment protocols.

Individualized education was provided to the study group patients by face-to-face counseling over one hour, based on the personality of the patient. The patient's knowledge on diabetes and self-care was assessed, and a tailored self-care plan was provided to each patient after the counseling. These plans were jointly developed by the nursing educators and a clinical psychologist in our hospital, covering dietary modification, exercises programs, adherence to medications, self-monitoring of blood glucose and blood pressure, and psychological counseling based on the four sub-groups of patients. In patients with stable extraversion personality, the education was focused on the importance of self-care plans, and adherence to medications. Patient's family members were encouraged to help with the monitoring of medication adherence. In patients with unstable extraversion personality, a more directive approach was used in identification of issues in self-care and management plans, and very specific therapeutic targets were set. In patients with stable introversion personality, a detailed explanation of the pathogenesis of diabetes, actions of medications and use of self-monitoring devices (e.g. home glucose monitor) were provided to address patient's concerns and queries. Patients with unstable introversion personality often showed lack of motivation in participating self-care and monitoring plans, therefore the education focus was to help them to understand the potential complications form sub-optimal diabetes management, thus motivating their participation of the management.
After the discharge, at the end of each calendar month, a follow-up was conducted in our hospital clinics for all patients, for a total of 6 months (Fig 1). At the middle of each calendar month (approximately two weeks before the hospital visit), a 10-min telephone interview was conducted by the nursing educators to all patients to address any issues or concerns the patients might have. All patients were invited to attend 3-monthly forum in the education facilities of our hospital. On the forum patients were encouraged to exchange views and ideas on diabetes self-care and discuss their progress in the management. The 2-h forums were facilitated by the nursing educators and a clinical psychologist who also addressed patients' concerns and questions.

With control group patients, one-hour face-to-face education sessions were provided in small groups (4-5 patients) during hospitalization. These education sessions were conducted by the same group of nurses who delivered the education sessions to the study group. The content of the education was mainly on the general information on diabetes, dietary and life style modification, correct use and compliance of anti-diabetic medications and self-monitoring of blood sugar levels. No personality assessment was performed, and no individualized self-care plan was provided (Fig 1). The after-discharge monthly follow-ups and monthly telephone interviews were conducted in the same manner as in the study group. A 3-monthly education forum was also provided to all patients but no personality based counseling by a clinical psychologist was provided during these forums.

\section{Assessment of management outcomes}

Clinical examination was performed at each follow-up visits and laboratory tests were performed when clinically deemed necessary during each hospital visits. In each patient, the body mass index, waist circumference, blood pressure, fasting and post-prandial blood glucose, and blood lipid profile were assessed at the end of the 6-month study.

\section{Statistical analysis}

SPSS v13.0 was used for the statistical analysis. Quantitative variables are expressed as mean $\pm \mathrm{SD}$. Comparison of numerical data was performed by a paired student $t$ test. Fisher's exact test was used for the comparison of categorical data. $\mathrm{P}<0.05$ was considered statistically significant.

African Health Sciences Vol 16 Issue 4, December, 2016 


\section{Results}

\section{General findings}

In the study group, the number of patients with stable extraversion, unstable extraversion, stable introversion and unstable introversion personality was 55(37.1\%),
$12(8.1 \%), 54(36.5 \%)$, and $27(16.2 \%)$, respectively. Two patients from the study group $(1.4 \%)$ and two from the control group $(1.4 \%, \mathrm{P}>0.05)$ did not complete the 6-month follow up and were subsequently excluded from this study (Fig 1).

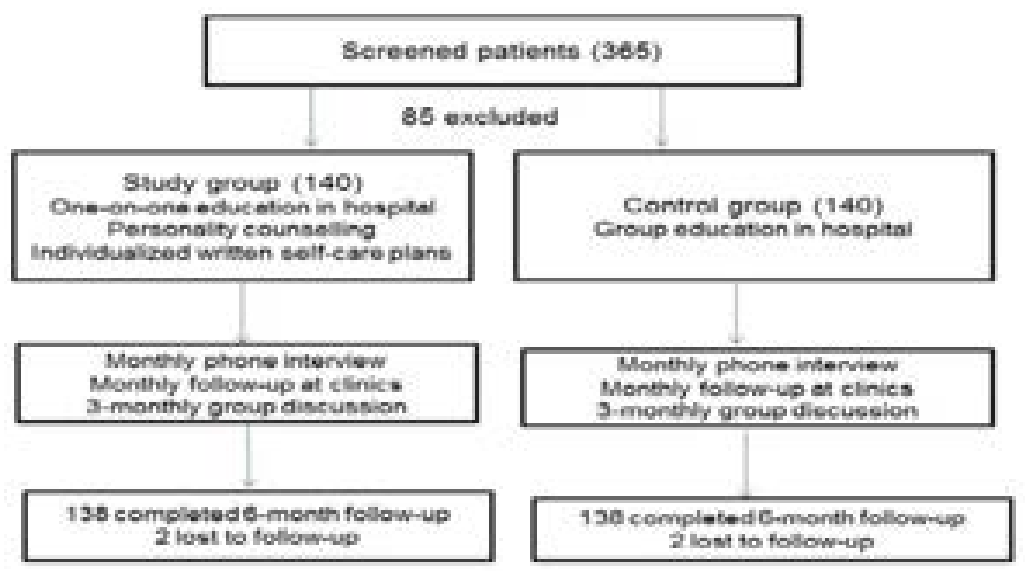

Figure 1. Flow chart of patient recruitment, randomization and follow-up

As shown in table 1, there was no statistically significant difference in age, sex, education level, duration of the T2DM, complications fromT2DM between the two groups before the study $(\mathrm{P}>0.05)$. The baseline body weight, blood glucose andlipids profile were also similar between the two groups $(\mathrm{P}>0.05)$.
Comparison of the clinical and biochemical outcomes The body mass index, waist circumference, fasting and post-prandial blood glucose, HbA1c, blood pressure, triglycerides and low-density lipoprotein in the study and control group six months after the intervention are listed in table 2.

\begin{tabular}{|c|c|c|c|}
\hline & $\begin{array}{l}\text { Study } \\
(\mathrm{n}=138)\end{array}$ & $\begin{array}{l}\text { Control } \\
(n=138)\end{array}$ & $P$ \\
\hline BMI $\left(\mathrm{kg} / \mathrm{m}^{2}\right)$ & $21.5 \pm 2.4$ & $23.6 \pm 1.5$ & 0.002 \\
\hline Waist circumference $(\mathrm{cm})$ & $83.7 \pm 6.4$ & $85.7 \pm 7.7$ & 0.032 \\
\hline $\begin{array}{l}\text { Fasting blood glucose } \\
(\mathrm{mmol} / \mathrm{L})\end{array}$ & $6.01 \pm 0.76$ & $6.93 \pm 2.13$ & 0.004 \\
\hline $\begin{array}{l}\text { Post-prandial glucose } \\
(\mathrm{mmol} / \mathrm{L})\end{array}$ & $7.52 \pm 1.54$ & $8.82 \pm 1.32$ & 0.048 \\
\hline $\mathrm{HbAlc}$ & $6.21 \pm 0.56$ & $6.95 \pm 3.12$ & 0.027 \\
\hline $\mathrm{SBP}(\mathrm{mm} \mathrm{Hg})$ & $130.1 \pm 8.8$ & $135.1 \pm 8.4$ & 0.003 \\
\hline $\mathrm{DBP}(\mathrm{mmHg})$ & $80.1 \pm 10.3$ & $82.6 \pm 8.8$ & 0.082 \\
\hline Triglyceride $(\mathrm{mmol} / \mathrm{L})$ & $1.21 \pm 0.66$ & $1.46 \pm 0.58$ & 0.037 \\
\hline $\mathrm{LDL}(\mathrm{mmol} / \mathrm{L})$ & $2.36 \pm 0.44$ & $2.84 \pm 0.64$ & 0.032 \\
\hline $\mathrm{HDL}(\mathrm{mmol} / \mathrm{L})$ & $1.21 \pm 0.14$ & $1.40 \pm 0.19$ & 0.22 \\
\hline Total cholesterol(mmol/L) & $4.26 \pm 0.76$ & $4.44 \pm 1.23$ & 0.038 \\
\hline
\end{tabular}

BMI: Body mass index. SBP and DBP: systolic and diastolic blood pressure; LDL and HDL:

Within each group, compared with the baseline value, there was a statistically significant reduction in body mass index, waist circumference, fasting and post-prandial blood glucose, systolic and diastolic blood pressure at the end of the trial $(\mathrm{P}<0.01)$. There was also a reduction in total cholesterol, triglyceride and low-density lipopro- tein at the end of the study $(\mathrm{P}<0.01)$. However, the level of high-density lipoprotein in each group remained unchanged $(\mathrm{P}>0.05)$.

At the end of the trial, the body mass index, waist circumference, fasting and postprandial blood glucose and HbA1c in the study group were lower than in the con- 
trol group (table 2, $\mathrm{P}<0.05$ or $<0.01$ ). The systolic blood pressure, triglyceride, low-density lipoprotein and total cholesterol in the study group were also lower than in the control group (table $2, \mathrm{P}<0.05$ or $<0.01$ ). There was no statistically significant difference in the mean diastolic blood pressure and high-density lipoprotein between the two groups (table 2, $\mathrm{P}>0.05$ ).

\section{Discussion}

The main findings of the present study are that in comparison with group education, individualized diabetes education tailored to patients' personality was associated with a greater reduction in fasting and post-prandial blood glucose. Individualized diabetes education was also associated with a greater reduction in body weight index, waist circumference, systolic blood pressure and blood cholesterol.

The association between patients' personality and diabetes control appears complex and controversial. A previous clinical trial found that lower average blood glucose values at baseline were associated with higher scores for neuroticism and several specific traits including anxiety, angry hostility, depression, self-consciousness, and vulnerability. ${ }^{3}$ One explanation for these relations between personality and blood sugar level was that people with higher neuroticism scores are more prone to experience negative emotions, which may provide increased motivation for a patient to follow self-care regimen and achieve a better clinical outcome. ${ }^{3}$

However, another study found that high neuroticism scores were associated with a higher level of glycosylated haemoglobin concentrations in patients with T1DM. ${ }^{4} \mathrm{~Pa}-$ tients with "dramatic-dependent" personality had a poor metabolic control. ${ }^{10}$ Taken together, adverse psychosocial factors and personality traits may be associated with poor control of diabetes, probably through poor adherence to therapeutic regimens including life style modifications. ${ }^{5}$ In the present study, we divided the study group patients into four personality categories, and provided one-onone counselling and individualized self-care plans to each patient. This was reinforced by a monthly clinic visit and a monthly telephone interview. After 6 months of intervention, the fasting and postprandial blood glucose levels and HbA1c in the study group were lower than in the control group. The body mass index, waist circumferences, systolic blood pressure and blood triglyceride or low-density lipoprotein levels in the study group were also lower than in the control group. These results suggest that in patients with T2DM, individualized education programs taking into consideration the personality of the patients are associated with better management outcomes than group education alone.

The reasons for the improved outcomes in the study group may be multifactorial. The individualized education or counseling, together with a written self-care plan based on the patient's personality, may have improved patients' motivation in adhering to dietary and life style modification measures. This is supported by a greater reduction in body weight mass index and waist circumferences, which are known to facilitate blood glucose, cholesterol and blood pressure control in diabetics. ${ }^{11,12}$ Furthermore, a recent study demonstrated that the diabetes knowledge was closely associated with medication adherence and good glycemic control. ${ }^{13}$ Although medication adherence was not assessed in the present study, it is likely that the individualized education and self-care plans may have improved patients' adherence to hypoglycemic and cardiovascular medications, which in turn led to a better blood glucose, blood pressure and lipids control.

It is worth noting that there was also a statistically significant reduction in blood glucose, HbA1c, blood pressure and cholesterol in the control group at the end of this study. These results suggest that group education with regular follow-ups is effective and should be considered as part of the integrated management plans for T2DM. However, in a primary health setting, the effect of group education on diabetes control seems uncertain. A structured group education program for patients with newly diagnosed T2DM resulted in greater improvements in weight loss and smoking cessation, but made no significant difference in $\mathrm{HbA} 1 \mathrm{c}$ levels 12 months or 3 years after the intervention. ${ }^{14,15}$ The lack of long-term effect on blood glucose control in these reports was probably related to the nature of education programs which were offered as a one-off short course. ${ }^{14,15}$ In our study, education sessions for the control group commenced during hospitalization, and were reinforced by monthly follow-ups and three-monthly forum discussions. Our findings are supported by other studies that regular education programs every 3 months were associated with persistent clinical, psychological and cognitive improvements in patients with T2DM. ${ }^{16,17}$

African Health Sciences Vol 16 Issue 4, December, 2016 


\section{Conclusion}

Regular education programs in patients with T2DM are associated with improved blood glucose control, and reduction in cardiovascular risk factors such as body mass index, blood pressure and cholesterol. Individualized education programs incorporating personality of the patients seem to offer better management outcomes than group education alone.

\section{Conflict of interest}

None to declare.

\section{References}

1. Gagliardino JJ, Aschner P, Baik SH, Chan J, Chantelot JM, Ilkova H, Ramachandran A. IDMPS investigators. Patients' education and its impact on care outcomes, resource consumption and working conditions: data from the International Diabetes Management Practices Study (IDMPS). Diabetes Metab 2012;38:128-134.

2. Banerjee M, Macdougall M, Lakhdar AF. Impact of a single one-to-one education session on glycemic control in patients with diabetes. J Diabetes 2012; 4:186-190 PubMed.

3. Lane JD, McCaskill CC, Williams PG, Parekh PI, Feinglos MN, Surwit RS. Personality correlates of glycemic control in type 2 diabetes. Diabetes Care 2000; 23:13211325 PubMed.

4. Gordon D, Fisher SG, Wilson M, Fergus E, Paterson KR, Semple CG. Psychological factors and their relationship to diabetes control. Diabet Med 1993; 10:530-534 PubMed.

5. Chida Y, Hamer M. An association of adverse psychosocial factors with diabetes mellitus: a meta-analytic review of longitudinal cohort studies. Diabetologia 2008; 51:2168-2178 PubMed.

6. Surwit RS, van Tilburg MA, Zucker N, McCaskill CC, Parekh P, Feinglos MN, Edwards CL, Williams P, Lane JD. Stress management improves long-term glycemic control in type 2 diabetes. Diabetes Care 2002; 25:30-34 PubMed.

7. Boersma GJ, Benthem L, van Beek AP, van Dijk G, Scheurink AJ. Personality, a key factor in personalized medicine?. Eur J Pharmacol 2011; 667:23-25 PubMed.

8. Hawthorne K, Robles Y, Cannings-John R, Edwards AGK. Culturally appropriate health education for type 2 diabetes mellitus in ethnic minority groups. Cochrane Database Syst Rev 2008; 16:CD006424.

9.Hans Jürgen Eysenck, Sybil B. G. Eysenck. Manual of the Eysenck Personality Questionnaire. London: Hodder and Stoughton, 1975.

African Health Sciences Vol 16 Issue 4, December, 2016
10. Orlandini A, Pastore MR, Fossati A, Clerici S, Sergi A, Balini A, Parlangeli MA, Maffei C, Secchi A, Pozza G. Effects of personality on metabolic control in IDDM patients. Diabetes Care 1995;18:206-9 PubMed.

11. Shantha GP, Kumar AA, Kahan S, Cheskin LJ. Association between glycosylated hemoglobin and intentional weight loss in overweight and obese patients with type 2 diabetes mellitus: a retrospective cohort study. Diabetes Educator 2012; 38:417-426 PubMed.

12. Unick JL, Beavers D, Jakicic JM, Kitabchi AE, Knowler WC, Wadden TA, Wing RR. Look AHEAD Research Group. Effectiveness of lifestyle interventions for individuals with severe obesity and type 2 diabetes: results from the Look AHEAD trial. Diabetes Care 2011; 34:21522157 PubMed.

13. Al-Qazaz HKh, Sulaiman SA, Hassali MA, Shafie AA, Sundram S, Al-Nuri R, Saleem F. Diabetes knowledge, medication adherence and glycemic control among patients with type 2 diabetes. Inter J Clin Pharm 2011; 33:1028-1035 PubMed.

14. Davies MJ, Heller S, Skinner TC, Campbell MJ, Carey ME, Cradock S, Dallosso HM, Daly H, Doherty Y, Eaton S, Fox C, Oliver L, Rantell K, Rayman G, Khunti K; Diabetes Education and Self Management for Ongoing and Newly Diagnosed Collaborative. Effectiveness of the diabetes education and self management for ongoing and newly diagnosed (DESMOND) programme for people with newly diagnosed type 2 diabetes: cluster randomised controlled trial. BMJ 2008; 336:491-5 PubMed.

15. Khunti K, Gray LJ, Skinner T, Carey ME, Realf K, Dalloso H, Fisher H, Campbell M, Heller S, Davies MJ. Effectiveness of a diabetes education and self management programme (DESMOND) for people with newly diagnosed type 2 diabetes mellitus: three year follow-up of a cluster randomised controlled trial in primary care. BMJ 2012;344:e2333

16. Trento M, Borgo E, Kucich C, Passera P, Trinetta A, Charrier L, Cavallo F, Porta M. Quality of life, coping ability, and metabolic control in patients with type 1 diabetes managed by group care and a carbohydrate counting program. Diabetes Care 2009;32:e134

17. Trento M, Gamba S, Gentile L, Grassi G, Miselli V, Morone G, Passera P, Tonutti L, Tomalino M, Bondonio P, Cavallo F, Porta M; for the ROMEO investigators. Rethink Organization To Improve Education And Outcomes (ROMEO). A Multicentre Randomised Trial Of Lifestyle Intervention By Group Care To Manage Type 2 Diabetes. Diabetes Care 2010;33:745-747 PubMed. 